\title{
MANAJEMEN LABA DAN PERENCANAAN PAJAK SEBAGAI SUMBER LARGE POSITIVE BOOK-TAX DIFFERENCES TERHADAP PERSISTENSI LABA
}

\author{
Liean Winata Merrysa \\ Universitas Trilogi \\ lieanwm15@gmail.com \\ Nurul Aisyah Rachmawati \\ Universitas Trilogi \\ nurulaisyah@universitas-trilogi.ac.id
}

\begin{abstract}
This study replicates Blaylocket al. (2012). Through this research, the writer wanted to analyze the influence of earnings management and tax planning as source of Large Positive BookTax Differences (LPBTD) to earnings persistence. This research uses panel data of manufacturing companies listed on Indonesia Stock Exchange for the period of research year 2012-2013. The data is analyzed with Pooled Least Square. Unfortunately, the authors can not prove that earnings management as a source of LPBTD can weaken earnings persistence. The result of earnings persistence estimation is exactly the opposite. This condition may occur because the action of earnings management by managers is viewed in terms of efficiency contracting perspective. In addition, the authors also can not prove that tax planning as a source of LPBTD strengthens the profit persistence. According to Blaylock et al. (2012), this happens because the measurement of cash effective tax rate can not be reviewed only with period of 5 (five) years.
\end{abstract}

Keywords:Persistensi profit, profit management, tax planning, Large positive book-tax differences

\begin{abstract}
ABSTRAK :Penelitian ini mereplikasi penelitian Blaylocket al. (2012). Melalui penelitian ini, penulis ingin menganalisis pengaruh manajemen laba dan perencanaan pajak sebagai sumber Large Positive Book-Tax Differences (LPBTD) terhadap persistensi laba. Penelitian ini menggunakan data panel perusahaan manufaktur yang terdaftar di Bursa Efek Indonesia untuk periode penelitian tahun 2012-2013. Data tersebut dianalisis dengan Pooled Least Square.Sayangnya, penulis tidak dapat membuktikan bahwa manajemen laba sebagai sumber LPBTD dapat memperlemah persistensi laba. Hasil estimasi persistensi laba justru menunjukkan sebaliknya. Kondisi ini mungkin terjadi karena tindakan manajemen laba yang dilakukan manajer dipandang dari sisi efficiency contracting perspective. Selainitu, penulis juga tidak dapat membuktikan bahwa perencanaan pajak sebagai sumber LPBTD memperkuat persistensi laba. Menurut Blaylock et al. (2012), hal ini terjadi lantaran pengukuran cash effective tax rate tidak dapat ditinjau hanya dengan periode 5 (lima) tahun.
\end{abstract}

Kata Kunci: Persistensi laba, Manajemen laba, Perencanaan pajak, Large positive booktax differences

\section{Pendahuluan}

Informasi mengenai laba sangat penting bagi stakeholders suatu perusahaan, seperti investor, regulator, shareholders, kreditor, dan lain-lain. Laba perusahaan menjadi salah satu tolok ukur bagi investor yang ingin menanamkan investasinya. Laba juga menjadi dasar penghitungan pengenaan pajak yang nantinya akan disetorkan ke kas negara. Laba menjadi informasi yang sangat diperlukan bagi para shareholders karena merupakan dasar perusahaan untuk melakukan pengumuman dan pembagian dividen. Dengan demikian, sangat banyak manfaat dari informasi mengenai laba perusahaan. Selain itu, laba merupakan salah satu tujuan perusahaan 
untuk dapat beroperasi secara berkelanjutan (going concern).

Oleh sebab itu, kualitas laba suatu perusahaan sangat perlu untuk diperhatikan mengingat pentingnya informasi mengenai laba. Menurut Penman (2001), laba yang berkualitas adalah laba yang berkelanjutan di masa depan (sustainable earnings). Laba yang berkelanjutan sering kali diproksikan dengan persistensi laba (Hanlon, 2005; Blaylock et al., 2012). Persistensi laba adalah revisi dalam laba akuntansi yang diharapkan di masa depan (expected future earnings) yang diimplikasi oleh laba akuntansi tahun berjalan.

Informasi mengenai kualitas laba juga dapat tercermin dari besarnya Pajak Penghasilan $(\mathrm{PPh})$ perusahaan sebagaimana tersaji dalam laporan keuangan perusahaan. Perbedaan antara laba akuntansi dan laba fiskal (book-tax differences/BTD) sering dijadikan proksi untuk menangkap informasi mengenai kualitas laba tersebut. Perusahaan dengan BTD yang besar baik positif maupun negatif akan memperlemah kualitas laba (Hanlon, 2005). BTD juga dapat memberikan informasi mengenai kebijakan accrual discretion management.

Blaylock et al. (2012) mengembangkan penelitian Hanlon (2005) dengan memfokuskan sampel penelitiannya pada Large Positive Book Tax Differences (LPBTD). Menurut Blaylock et al. (2012), LPBTD menyediakan informasi yang penting mengenai persistensi laba. Implikasi dari LPBTD terhadap persistensi laba tersebut sangat dipengaruhi oleh 3 (tiga) sumber utama dari LPBTD.

Pertama, LPBTD dapat terjadi karena adanya manajemen laba. Manajer melakukan manajemen laba karena adanya motivasi tertentu, seperti bonus, politik, penawaran saham perdana (IPO), pasar modal, dan lain-lain (Scott, 2003). Motivasi ini dapat menimbulkan selisih antara laba akuntansi dan laba fiskal menjadi besar dan positif. Menurut Phillips et al. (2003), LPBTD sangat informatif mengenai manajemen laba. Dalam Hanlon (2005), jika LPBTD merupakan sinyal dari meningkatnya discretionary accruals, maka perusahaan dengan LPBTD akan menunjukkan persistensi laba yang lebih rendah.

Kedua, LPBTD dapat terjadi karena adanya strategi perencanaan pajak untuk meminimalkan pajak yang terutang. Strategi dasar dari perencanaan pajak adalah untuk menunda pajak selama mungkin agar dapat mengurangi nilai dari pajak yang telah dibayar (taxes paid). Strategi ini akan menyebabkan perusahaan berada dalam kondisi LPBTD. Ketiga, LPBTD juga dapat timbul karena adanya perbedaan yang wajar pada perlakuan pendapatan dan beban antara akuntansi dan perpajakan.

Blaylocket al. (2012) menggunakan manajemen laba dan perencanaan pajak sebagai sumber LPBTD yang menyediakan informasi penting mengenai persistensi laba dan persistensi akrual. Blaylock et al. (2012) menemukan bahwa perusahaan dengan LPBTD yang didominasi oleh manajemen laba memiliki persistensi laba yang rendah. Hal ini terjadi karena manajemen laba membuat laba perusahaan tidak dilaporkan sebagaimana mestinya sehingga informasi mengenai laba di masa depan menjadi tidak andal.

Sementara itu, perusahaan dengan LPBTD yang didominasi oleh perencanaan pajak menunjukkan persistensi laba yang positif dan signifikan. Hal ini terjadi karena perencanaan pajak bertujuan untuk menunda pajak selama mungkin agar nilai dari pajak yang dibayar dapat berkurang.

Berdasarkan latar belakang diatas, penulis akan mereplikasi penelitian Blaylock et al. (2012) melalui studi empiris pada perusahaan manufaktur yang terdaftar di Bursa Efek Indonesia 
(BEI) tahun 2012-2013. Pada penelitian ini, penulis ingin meneliti pengaruh manajemen laba dan perencanaan pajak sebagai sumber LPBTD terhadap persistensi laba. Penelitian mengenai pengaruh sumber LPBTD terhadap persistensi laba masih jarang diteliti di Indonesia. Sebagian besar masihterfokus pada pengaruhLPBTD terhadap persistensi laba saja, tanpa melihat sumbernya.

\section{Telaah Literatur Dan Pengembangan Hipotesis}

\section{Persistensi Laba}

Persistensi laba adalah revisi dalam laba akuntansi yang diharapkan di masa depan (expected future earnings) yang diimplikasi oleh laba akuntansi tahun berjalan (Penman, 2001). Menurut Jonas dan Blanchet (2000) dalam Hanlon (2005), persistensi laba merupakan salah satu komponen nilai prediksi laba dalam menentukan kualitas laba.Persistensi laba tersebut ditentukan oleh komponen akrual dan aliran kas dari laba sekarang, yang mewakili sifat transitori dan permanen laba (Sloan, 1996). Laba yang persisten adalah laba yang dapat mencerminkan keberlanjutan laba di masa depan (Penman, 2001).

Persistensi laba diukur dengan proksi yang berbeda-beda. Sloan (1996) menunjukkan bahwa persistensi laba merupakan hubungan antara kinerja laba masa kini dan kinerja laba masa depan. Dichev dan Tang (2008) mengukur persistensi laba berdasarkan hubungan antara Return on Assets (ROA) tahun ini terhadap ROA tahun depan. Blaylock et al. (2012) mengukur persistensi laba sebagai proksi kualitas laba dengan menganalisis pengaruh laba akuntansi sebelum pajak pada tahun ini terhadap labaakuntansi sebelum pajak pada tahun mendatang. Oleh karena penelitian ini mereplikasi Blaylock et al. (2012), maka persistensi laba menggunakan model 1 berikut:
$P T B I_{i t+1}=\gamma_{0}+\gamma_{1} P T B I_{i t}+\varepsilon_{i t+1} \ldots(1)$

di mana:

PTBI $_{i t+1}=$ Laba akuntansi sebelum pajak perusahaan i pada tahun $\mathrm{t}+1$

PTBI $_{\text {it }}=$ Labaakuntansi sebelum pajakperusahaan i pada tahun $\mathrm{t}$

\section{Large Positive Book-Tax Differences}

Dalam satu periode, perusahaan diwajibkan untuk membuat laporan keuangan. Dalam hal ini, laporan keuangan disusun berdasarkan Pernyataan Standar Akuntansi Keuangan (PSAK). Tujuan laporan keuangan berdasarkan PSAK nomor 1 adalah untuk memberikan informasi mengenai posisi keuangan, arus kas. Untuk tujuan perpajakan, laporan keuangan yang semula disusun berdasarkan PSAK direkonsiliasi fiskal agar sesuai dengan undang-undang perpajakan yang berlaku. Menurut Hery (2014), rekonsiliasi fiskal merupakan proses penyesuaian laba akuntansi untuk mendapatkan penghasilan neto yang sesuai dengan ketentuan perpajakan (laba fiskal). Kemudian, laba fiskal akan dijadikan dasar untuk penghitungan Pajak Penghasilan yang terutang.

LPBTD merupakan perbedaan positif yang besar antara laba akuntansi dan laba fiskal. Menurut Blaylock et al. (2012), perbedaan positif yang timpang antara laba menurut akuntansi dan laba menurut pajak ini dikarenakan 3 (tiga) sumber utama dari LPBTD. Pertama, LPBTD dapat terjadi karena adanya manajemen laba. Manajer melakukan manajemen laba karena adanya motivasi tertentu, seperti bonus, politik, penawaran saham perdana (IPO), pasar modal, dan lain-lain (Scott, 2003). Motivasi ini dapat menimbulkan selisih antara laba akuntansi dan laba fiskal menjadi besar dan positif. Menurut Phillips et al. (2003), LPBTD sangat informatif mengenai manajemen laba. Dalam Hanlon (2005), jika LPBTD merupakan 
sinyal dari meningkatnya discretionary accruals, maka perusahaan dengan LPBTD akan menunjukkan persistensi laba yang lebih rendah.

Kedua, LPBTD dapat terjadi karena adanya strategi perencanaan pajak (taxplanning strategy) untuk meminimalkan pajak yang terutang. Strategi dasar dari perencanaan pajak adalah untuk menunda pajak selama mungkin agar dapat mengurangi nilai dari pajak yang telah dibayar (taxes paid). Strategi ini akan menyebabkan perusahaan berada dalam kondisi LPBTD. Blaylock et al. (2012) mengeluarkan opini bahwa LPBTD yang bersumber dari perencanaan pajak akan menunjukkan persistensi laba masa depan yang tinggi.

Ketiga, LPBTD juga dapat timbul karena adanya perbedaan yang wajar pada perlakuan pendapatan dan beban antara akuntansi dan perpajakan (Scholes et al., 2008). Akuntansi yang berbasis PSAK dan perpajakan yang berbasis undangundang perpajakan memiliki peraturan tersendiri yang kemudian secara alami akan timbul perbedaan dan konsekuensi perpajakan di masa kini dan masa mendatang.

\section{Manajemen Laba}

Menurut Schipper (1989), manajemen laba adalah suatu intervensi yang sengaja dilakukan oleh manajemen dengan tujuan tertentu terhadap proses pelaporan laba dan tidak jarang dilakukan untuk mendapatkan keuntungan pribadi. Menurut Schroeder et al. (2009), manajemen laba adalah usaha yang dilakukan manajemen perusahaan untuk memengaruhi laba jangka pendek yang dilaporkan pada laporan keuangan. Wild et al. (2007) menyatakan bahwa manajemen laba merupakan tindakan manajemen di mana manajer melakukan manipulasi terhadap laba yang ada di dalam laporan keuangan (window dressing).
Menurut Holthausen (1990) terdapat dua konsep dalam memahamimanajemen laba. Dua konsep tersebut merupakan dua kondisi yang salingmelengkapai dalam memahami manajemen laba. Manajer memilih prosedurakuntansi tertentu dengan alasan yang dapat diklasifikasikan menjadiefisien jika manajemen laba diperuntukkan memaksimumkan nilaiperusahaan, dan oportunistik jika manajemen laba diperuntukkan untukkepentingan pribadi manajer. Perilaku manajer tersebut dapat dijelaskansebagai berikut:

a. Manajemen laba dipandang sebagai opportunistic behavior perspectivejika manajer memaksimumkan kepentingannya dalam menghadapikontrak kompensasi, kontrak utang dan biaya politis.

b. Manajemen laba dipandang dari sisi efficiency contracting perspective biladalam kontrak kompensasi, perusahaan akan mengantisipasi insentifmanajer untuk mengelola laba melalui jumlah kompensasi yangditawarkan. Lender juga akan melakukan hal yang sama dalammemutuskan tingkat bunga yang diminta. Dalam pandangan ini manajemen laba memberikan fleksibilitas kepada manajer untuk melindungi diri mereka dan perusahaan dalam menghadapi realisasikeadaan yang tidak dapat diantisipasi untuk menguntungkan semuapihak yang terlibat dalam kontrak (Scott,1997).

Dalam penelitianWatts dan Zimmerman (1986), teori akuntansi positif (positive accounting theory) menjabarkan 3 (tiga) hipotesis motivasi manajemen laba, yaitu: 1) hipotesis program bonus (the bonus plan hypotesis); 2) hipotesis perjanjian hutang (the debt covenant hypotesis); dan 3) hipotesis biaya politik (the political cost hypotesis).Dalam Scott (2003), beberapa motivasi yang mendorong manajer untuk melakukan 
manajemen laba, antara lain sebagai berikut: 1) motivasi bonus; 2) motivasi kontrak; 3) motivasi politik; 4) motivasi pajak; 5) pergantian CEO (Chief Executive Officer); 6) penawaran saham perdana (IPO); dan 7) motivasi pasar modal.

\section{Perencanaan Pajak}

Perencanaan pajak merupakan suatu kapasitas yang dimiliki oleh Wajib Pajak dalam menyusun aktivitas keuangan untuk mendapatkan pengeluaran atau beban pajak seminimal mungkin (Nugraha, 2014). Perencanaan pajak juga dikenal sebagai effective tax planning (perencanaan pajak yang efektif). Dalam hal ini, Wajib Pajak berusaha mendapatkan penghematan pajak melalui prosedur penghindaran pajak secara sistematis sesuai dengan ketentuan undang-undang perpajakan (Hoffman, 1961).Menurut Lumbantoruan (2007), perencanaan pajak merupakan salah satu fungsi dari manajemen pajak. Manajemen pajak merupakan sarana untuk memenuhi kewajiban perpajakan sesuai dengan ketentuan perpajakan yang berlaku, tetapi jumlah pajak yang dibayarkan dapat ditekan seminimal mungkin.

Pada dasarnya perencanaan pajak harus memenuhi ketentuan-ketentuan berikut: 1) tidak melanggar aturan perpajakan; 2) dapat diterima secara bisnis; dan 3) buktibukti pendukung yang memadai. Menurut Suandy (2011), faktor-faktor yang memotivasi perusahaan melakukan perencanaan pajak, yaitu: 1) kebijakan perpajakan; 2) undang-undang perpajakan; 3) administrasi perpajakan; 4) loopholes; dan 5) tarif pajak.

\section{Pengembangan Hipotesis}

Penelitian Blaylock et al. (2012) bertujuan untuk mengetahui pengaruh manajemen laba dan perencanaan pajak sebagai sumber LPBTD terhadap persistensi laba dan persistensi akrual. Blaylock et al. (2012) kemudian beropini bahwa adanya keberagaman sumber LPBTD berpengaruh terhadap kualitas laba.Blaylock et al. (2012) mengembangkan penelitian Hanlon (2005) dengan memfokuskan pada Large Positive Book Tax Differences ( LPBTD). Dalam penelitian ini, Blaylock et al. (2012) menggunakan 2 (dua) pengelompokkan untuk mengelompokkan perusahaan yang dijadikan sampel dan memiliki LPBTD ke dalam kategori perusahaan yang melakukan manajemen laba atau penghindaran pajak.

Blaylock et al. (2012) menggunakan manajemen laba dan perencanaan pajak sebagai sumber LPBTD yang menyediakan informasi penting mengenai persistensi laba dan persistensi akrual. Blaylock et al. (2012) menemukan bahwa perusahaan dengan LPBTD yang didominasi oleh manajemen laba memiliki persistensi laba yang rendah. Hal ini terjadi karena manajemen laba membuat laba perusahaan tidak dilaporkan sebagaimana mestinya sehingga informasi mengenai laba di masa depan menjadi tidak andal.

Sementara itu, perusahaan dengan LPBTD yang didominasi oleh perencanaan pajak menunjukkan persistensi laba yang positif dan signifikan. Hal ini terjadi karena perencanaan pajak bertujuan untuk menunda pajak selama mungkin agar nilai dari pajak yang dibayar dapat berkurang.Penelitian ini akan mereplikasi penelitianBlaylock et al. (2012) dengan hipotesis sebagai berikut:

\section{$H_{1}$ : Manajemen laba sebagai sumber LPBTD memperlemah persistensi laba}

$\mathrm{H}_{2}:$ Perencanaan pajak sebagai
sumber LPBTD
persistensi laba




\section{Gambar 1}

\section{Kerangka Penelitian}

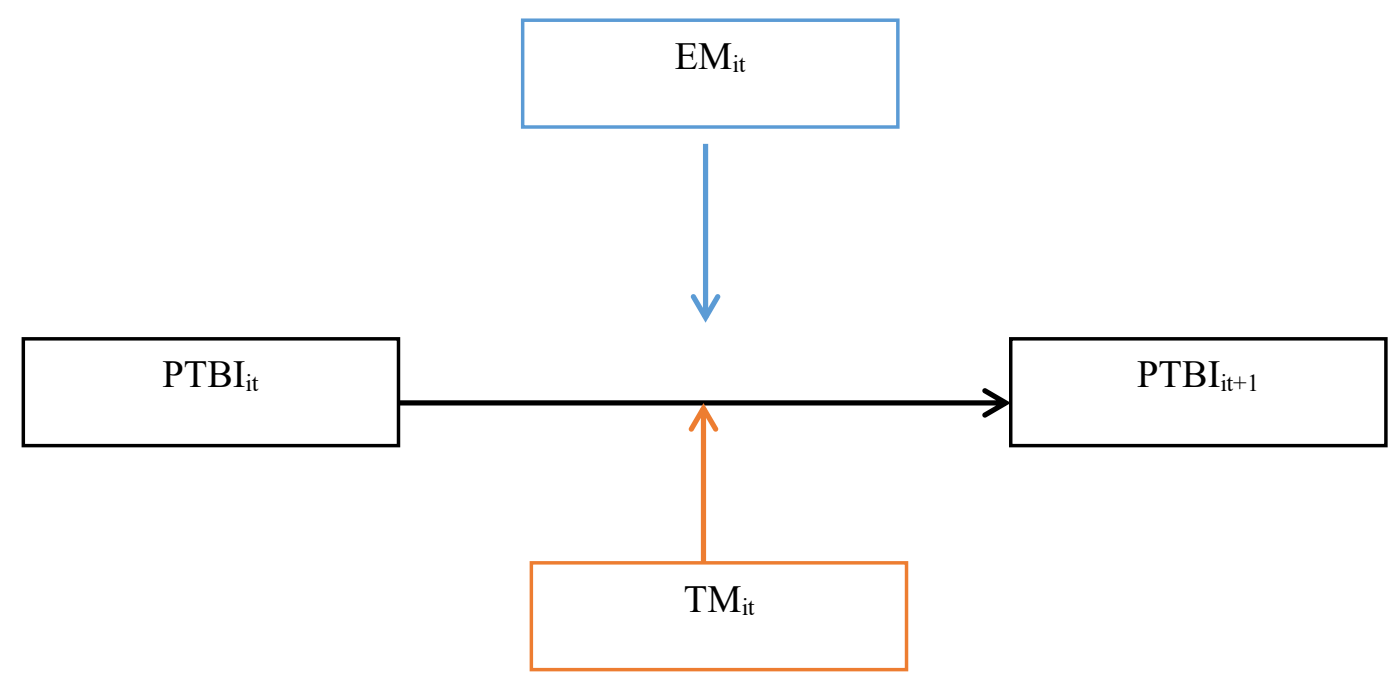

\section{Metode Penelitian}

Metode yang digunakan dalam penelitian ini adalah metode kuantitatif. Penelitian ini menggunakan analisis Pooled Least Square (PLS) yang diolah dengan SPSS 22.0. Pasalnya, penelitian ini menggunakan data panel, yaitu kombinasi antara data time series dan cross section.

\section{Data dan Sampel}

Sampel yang digunakan pada penelitian ini didapatkan dari laporan keuangan perusahaan manufaktur yang terdaftar di website resmi Bursa Efek Indonesia (BEI) untuk periode penelitian tahun 2012-2013. Klasifikasi industri manufaktur ditetapkan berdasarkan Jasica Index. Setelah dilakukan seleksi, diperoleh jumlah sampel yang memenuhi kriteria yang diperlukan dalam penelitian, yaitu sebanyak 42 perusahaan-tahun. Data pemilihan sampel ditampilkan di dalam Tabel 1. 
Tabel 1

Hasil Pemilihan Sampel

\begin{tabular}{|c|l|c|}
\hline No. & \multicolumn{1}{|c|}{ Keterangan } & Jumlah \\
\hline 1. & Perusahaan manufaktur yang terdaftar dari tahun 2008-2014 & 192 \\
\hline 2. & $\begin{array}{l}\text { Perusahaan manufaktur yang tidak memiliki laporan keuangan } \\
\text { auditan lengkap tahun 2008-2014 }\end{array}$ & 6 \\
\hline 3. & $\begin{array}{l}\text { Perusahaan manufaktur yang tidak memiliki periode laporan } \\
\text { keuangan 1 Januari - 31 Desember }\end{array}$ & 2 \\
\hline 4. & $\begin{array}{l}\text { Perusahaan manufaktur yang menggunakan mata uang asing } \\
\text { pada tahun 2008-2014 }\end{array}$ & 13 \\
\hline 5. & $\begin{array}{l}\text { Perusahaan yang melakukan reorganisasi dan kuasi reorganisasi } \\
\text { pada tahun 2008-2014 }\end{array}$ & 46 \\
\hline 6. & $\begin{array}{l}\text { Perusahaan yang tidak memiliki data yang dibutuhkan dalam } \\
\text { penelitian }\end{array}$ & 84 \\
\hline 7. & Total perusahaan manufaktur yang memenuhi kriteria & 42 \\
\hline 8. & Total (84 perusahaan x 2 tahun) & $\begin{array}{l}\text { Sampel perusahaan yang berada dalam kondisi LPBTD pada } \\
\text { kuartil (25\%) teratas pada tahun 2012-2013 }\end{array}$ \\
\hline 9. &
\end{tabular}

\section{Penyusunan Sampel LPBTD}

Sampel penelitian ini fokus pada LPBTD sebagaimana penelitian Blaylock et al. (2012). Untuk mengukur LPBTD, penulis terlebih dahulu menghitung temporary BTD (TBTD) dari semua perusahaan manufaktur yang memenuhi kriteria-kriteria penelitian. TBTD adalah proksi untuk mengukur perbedaan antara laba akuntansi dan laba fiskal. Pada penelitian ini, TBTD merupakan perbedaan temporer laba akuntansi dan laba fiskal perusahaan i pada tahun t yang dibagi dengan rata-rata total aset.TBTD perusahaan manufaktur per tahun kemudian diranking dari yang terbesar hingga yang terkecil. Kuartil (25\%) teratas merupakan perusahaan yang berada dalam kondisi LPBTD. Perusahaan pada kelompok inilah yang digunakan sebagai sampel penelitian.
Model penelitian yang digunakan mereplikasi model penelitian Blaylock et al. (2012). Berikut ini adalah model penelitian yang digunakan:

$$
\begin{gathered}
P T B I_{i t+1}=\gamma_{0}+\gamma_{1} E M_{i t}+\gamma_{2} T P_{i t}+ \\
\gamma_{3} P T B I_{i t}+\gamma_{4} P T B I_{i t} \times E M_{i t}+ \\
\gamma_{5} P T B I_{i t} \times T P_{i t}+\varepsilon_{i t+1} \ldots(2)
\end{gathered}
$$

di mana:

PTBI $_{\mathrm{it}+1}=$ laba sebelum pajakperusahaan i pada tahun $\mathrm{t}+1$

$\mathrm{EM}_{\mathrm{it}} \quad=$ variabel dummy untuk perusahaan i pada tahun t, dimana 1 adalah perusahaan yang berada dalam kondisi EM dan 0 adalah lainnya

\section{Model Penelitian}


$\mathrm{TP}_{\mathrm{it}}$

$=$ variabel dummy untuk

perusahaan i yang

melakukan TPpada

tahun $\mathrm{t}$, dimana 1 adalah

perusahaan yang berada dalam kondisi TP dan 0 adalah lainnya

$\mathrm{PTBI}_{\mathrm{it}}$

$=$ laba sebelum pajakperusahaan i pada tahun $\mathrm{t}$

Setiap variabel kecuali variabel $\mathrm{EM}_{\mathrm{it}}$ dan $\mathrm{TP}_{\text {it }}$ dibagi dengan rata-rata total aset untuk mengontrol ukuran perusahaan.

Koefisien $\gamma_{3}$ pada PTBI $_{t}$ merepresentasikan persistensi laba tahun-perusahaan dengan LPBTD yang masuk dalam lainnya. Untuk menguji $\mathrm{H}_{1}$, pengaruh manajemen laba sebagai sumber LPBTD tercermin pada $\gamma_{4}$. Penulis memprediksi bahwa $\gamma_{4}$ bernilai negatif. Hal ini berarti bahwa manajemen laba sebagai sumber LPBTD memperlemah persistensi laba. Dengan kata lain, kualitas laba perusahaan yang melakukan manajemen laba sehingga berada dalam kondisi LPBTD lebih rendah dibandingkan dengan perusahaan yang tidak berada dalam kelompok EM (Blaylock et al., 2012).

Untuk menguji $\mathrm{H}_{2}$, pengaruh perencanaan pajak sebagai sumber LPBTD tercermin pada $\gamma_{5}$. Penulis memprediksi bahwa $\gamma_{5}$ bernilai positif. Hal ini berarti bahwa perencanaan pajak sebagai sumber LPBTD memperkuat persistensi laba. Dengan kata lain, kualitas laba perusahaan yang melakukan perencanaan pajak sehingga berada dalam kondisi LPBTD lebih tinggi dibandingkan dengan perusahaan yang tidak berada dalam kelompok TP (Blaylock et al., 2012).

\section{Operasional Variabel Penelitian}

\section{Variabel Dependen}

Variabel dependen dalam penelitian ini adalah $\mathrm{PTBI}_{\mathrm{it}+1}$. Variabel ini diukur dengan laba akuntansi sebelum pajak untuk perusahaan $\mathrm{i}$ pada tahun $\mathrm{t}+1$ sebagaimana tersaji dalam laporan laba rugi perusahaan. Variabel $\mathrm{PTBI}_{\mathrm{it}+1}$ ini dibagi dengan rata-rata total aset untuk mengontrol ukuran perusahaan.

\section{Variabel Independen}

Variabel independen dalam penelitian ini adalah $\mathrm{PTBI}_{\mathrm{it}}$. Variabel ini diukur dengan laba akuntansi sebelum pajak untuk perusahaan i pada tahun $t$ sebagaimana tersaji dalam laporan laba rugi perusahaan. Variabel PTBI $_{\text {it }}$ dibagi dengan rata-rata total aset untuk mengontrol ukuran perusahaan.

\section{Variabel Moderasi}

Variabel moderasi yang digunakan pada penelitian ini adalah $\mathrm{EM}_{\mathrm{it}}$ dan $\mathrm{TP}_{\mathrm{it} .}$ Sebagaimana penelitian Blaylock et al. (2012), pengukuran $\mathrm{EM}_{\mathrm{it}}$ menggunakan model modified Jones. Besaran akrual diskresioner dalam sampel LPBTD akan diranking dari yang terbesar hingga terkecil. Perusahaan yang berada pada kuintil $(20 \%)$ teratas akan dikelompokkan sebagai perusahaan yang melakukan tindakan manajemen laba sehingga berada dalam kondisi LPBTD. Sementara itu, sisanya merupakan lainnya. Dengan demikian, $\mathrm{EM}_{\mathrm{it}}$ adalahvariabel dummy di mana 1 (satu) adalah perusahaan yang berada dalam kondisi EM dan 0 (nol) adalah perusahaan yang tidak berada dalam kondisi EM.

Sesuai dengan penelitian Blaylock et al. (2012), $\mathrm{TP}_{\mathrm{it}}$ diukur dengan cash effective tax rate pada perusahaan $i$ selama 5 tahun kebelakang dari tahun t. Cash effective tax rate merupakan rasio pembayaran pajak terhadap laba akuntansi setelah pajak.Setelah cash effective tax rate ditentukan, kemudian diurutkan dari yang terbesar hingga yang terkecil untuk tiap tahunnya. Perusahaan yang berada dalam kuintil (20\%) terbawah merupakan kelompok $\mathrm{TP}_{\mathrm{it}}$. Sementara sisanya masuk dalam kelompok lainnya. Dengan demikian, variabel $\mathrm{TP}_{\text {it }}$ adalahvariabel dummy di mana 1 (satu) adalah perusahaan yang berada dalam kondisi 
TP dan 0 (nol) adalah perusahaan yang tidak berada dalam kondisi TP.

\section{Analisis Hasil Penelitian}

\section{Analisis Statistik Deskriptif}

Tabel 2 menyajikan hasil statistik deskriptif dari setiap variabel yang digunakan dalam penelitian ini. Berdasarkan Tabel 2, nilai rata-rata laba akuntansi sebelum pajak perusahaan i pada tahun $\mathrm{t}+1$ sebesar 0,1158 . Hal tersebut menunjukkan bahwa terjadi penurunan laba pada tahun $\mathrm{t}+1$ dibandingkan laba akuntansi sebelum pajak perusahaan i pada tahun t. Nilai minimum dan maksimum variabel $\mathrm{PTBI}_{\mathrm{it}+1}$ adalah $-0,15$ dan 0,64 yang menandakanadanya perusahaan yang mengalami kerugian dengan nilai minimum $-0,15$ dan perusahaan yang memiliki keuntungan dengan nilai maksimum 0,64 .

Berdasarkan tabel di atas, rata-rata $\mathrm{PTBI}_{\mathrm{it}}$ sebesar 0,1354 dengan standar deviasi $12,516 \%$. Hal tersebut menunjukkan bahwa nilai laba akuntansi sebelum pajak perusahaan i pada tahun $\mathrm{t}$ tidak terlalu jauh berbeda dari rata-ratanya. Nilai laba akuntansi sebelum pajak perusahaan i pada tahun $t$ yang paling kecil adalah sebesar 0,00 dan nilai yang besar adalah sebesar 0,58. Hal tersebut terjadi karena penelitian ini hanya fokus di perusahaan yang mendapatkan laba pada tahun berjalan. Menurut Penman (2001), laba yang persisten adalah laba yang dapat mencerminkan keberlanjutan laba di masa depan. Oleh karena itu, penelitian ini memfokuskan pada perusahaan yang laba.

Rata-rata $\mathrm{EM}_{\text {it }}$ dan $\mathrm{TP}_{\text {it }}$ sebesar .2381 dengan standar deviasi 43,108\%. Hal tersebut menunjukkan bahwa nilai dummy $\mathrm{EM}_{\mathrm{it}}$ dan $\mathrm{TP}_{\mathrm{it}}$ cukup berbeda dengan nilai rata-rata $\mathrm{EM}_{\mathrm{it}}$ dan $\mathrm{TP}_{\text {it. }}$ Nilai minimumEM $M_{i t}$ dan $\mathrm{TP}_{\text {it }}$ sebesar 0,00 dan nilai maksimum $\mathrm{EM}_{\mathrm{it}}$ dan $\mathrm{TP}_{\mathrm{it}}$ adalah sebesar 1,00. Rata-rata variabel $\mathrm{PTBI}_{\mathrm{it}} \mathrm{XEM}_{\mathrm{it}}$ adalah sebesar 0,0222 dengan standar deviasi $4,851 \%$. Hal tersebut menunjukkan bahwa nilai variabelPTBI ${ }_{i t} x E M_{i t}$ tidak terlalu jauh berbeda dari rata-ratanya. NilaiPTBI ${ }_{i t} X M_{i t}$ yang paling kecil adalah sebesar 0,00 dan nilai yang paling besar adalah sebesar 0,17 .

Rata-rata variabel $\mathrm{PTBI}_{\mathrm{it}} \mathrm{XTP}_{\text {it }}$ adalah sebesar 0,0315 dengan standar deviasi $9,755 \%$. Hal tersebut menunjukkan bahwa nilai variabelPTBI ${ }_{i t} X{ }_{i t}$ tidak terlalu jauh berbeda dari rata-ratanya. EM adalah dummy variabel dimana 1 (satu) adalah perusahaan yang berada dalam kondisi EM dan 0 (nol) adalah perusahaan yang tidak berada dalam kondisi EM. TP adalah dummy variabel dimana 1 (satu) adalah perusahaan yang berada dalam kondisi TP dan 0 (nol) adalah perusahaan yang tidak berada dalam kondisi TP. NilaiPTBI ${ }_{i t} x P_{\text {it }}$ yang paling kecil adalah sebesar 0,00 dan nilai yang paling besar adalah sebesar 0,57.

Tabel 2

\section{Hasil Uji Statistik Deskriptif}

\begin{tabular}{|l|r|r|r|r|r|}
\hline & $\mathrm{N}$ & Minimum & Maximum & Mean & Std. Deviation \\
\hline PTBI $_{i t}$ & 42 & .00 & .58 & .1354 & .12516 \\
\hline PTBI $_{i t}$ & 42 & -.15 & .64 & .1158 & .15949 \\
\hline PTBI $_{i t} x{ }^{2}$ & & .00 & .17 & .0222 & .04851 \\
\hline
\end{tabular}




\begin{tabular}{|l|r|r|r|r|r|}
\hline PTBI $_{\text {it }} \mathrm{XTP}_{\text {it }}$ & 42 & .00 & .57 & .0315 & .09755 \\
\hline $\mathrm{EM}_{\mathrm{it}}$ & 42 & .00 & 1.00 & .2381 & .43108 \\
\hline $\mathrm{TP}_{\mathrm{it}}$ & 42 & .00 & 1.00 & .2381 & .43108 \\
\hline Valid N (listwise) & 42 & & & & \\
\hline
\end{tabular}

Sumber: Hasil pengolahan data

\section{Uji Multikolinearitas}

Metode yang digunakan pada penelitian ini adalah dengan melihat nilai VIF (Variance Inflation Factor) dan Tolerance yang terdapat pada kolom collinearity statistic yang dihasilkan dari SPSS 22.0. Jika nilai Tolerance $<0,10$ atau sama dengan VIF $>10$, maka terdapat multikolinearitas (Ghozali,
2009). Tabel 3 menunjukkan hasil pengujian multikolinearitas pada variabel independen yang digunakan dalam penelitian ini.Berdasarkan Tabel 3, tidak ada variabel independen yang memiliki nilai Tolerance $<0,10$ dan tidak ada yang memiliki VIF $>10$. Maka dapat disimpulkan bahwa model regresi terbebas dari multikolinearitas dan dapat digunakan dalam penelitian.

Tabel 3

\section{Hasil Uji Multikolinearitas}

\begin{tabular}{|l|l|c|l|}
\hline \multicolumn{1}{|c|}{$\begin{array}{c}\text { Variabel } \\
\text { Penelitian }\end{array}$} & $\begin{array}{c}\text { Nilai } \\
\text { Tolerance }\end{array}$ & $\begin{array}{c}\text { Nilai } \\
\text { VIF }\end{array}$ & \multicolumn{1}{|c|}{ Kesimpulan } \\
\hline EM $_{\mathrm{it}}$ & .278 & 3.591 & Bebas Multikolinearitas \\
\hline $\mathrm{TP}_{\mathrm{it}}$ & .511 & 1.957 & Bebas Multikolinearitas \\
\hline PTBI $_{\mathrm{it}}$ & .530 & 1.885 & Bebas Multikolinearitas \\
\hline PTBI $_{\mathrm{it} X E \mathrm{X}_{\mathrm{it}}}$ & .289 & 3.465 & Bebas Multikolinearitas \\
\hline PTBI $_{\mathrm{it} X \mathrm{XTit}}$ & .381 & 2.627 & Bebas Multikolinearitas \\
\hline
\end{tabular}

Sumber: Hasil pengolahan data

\section{Analisis Regresi}

Tabel 4 menyajikan hasil estimasi persistensi laba sesuai dengan persamaan 2. Dalam tabel tersebut diketahui bahwa nilai F-statistic sebesar 24,989 dengan probabilitas (F-statistic) atau p-value sebesar 0,0000 (lebih kecil dari $\alpha=1 \%$ ). Hal ini dapat disimpulkan bahwa variabel-variabel independen yang terdapat pada persamaan 2 secara bersama-sama memengaruhi variabel dependen pada tingkat kepercayaan $99 \%$. Hasil regresi persamaan 2 menghasilkan adjusted $\mathrm{R}^{2} \quad$ sebesar $0,745 \%$. Hal ini berarti bahwa $74,5 \%$ variasi laba akuntansi sebelum pajak perusahaan $\mathrm{i}$ pada tahun $\mathrm{t}+1$ mampu dijelaskan oleh variabel independen dalam persamaan tersebut. Sementara itu, sisanyadipengaruhi oleh variabelvariabel lain yang tidak terdapat dalam persamaan 2 .

Berdasarkan Tabel 4,penulis tidak dapat membuktikan hipotesis yang dikembangkan dalam penelitian ini. PadaH1 diprediksi bahwa manajemen laba sebagai sumber LPBTD akan 
memperlemah persistensi laba. Dalam hal ini, koefisien $\mathrm{PTBI}_{\mathrm{it}} \mathrm{xEM} \mathrm{M}_{\mathrm{it}}$ diprediksi bernilai negatif $\left(\gamma_{4}<0\right)$. Namun, hasil regresi justru menunjukkan sebaliknya, yaitu $\gamma_{4}$ bernilai positif sebesar 1,013 dan signifikan pada level $95 \%$. Dengan demikian, $\mathrm{H} 1$ ditolak.

Tidak sesuai dengan penelitian Blaylock et al. (2012), hasil ini menunjukkan bahwa kualitas laba perusahaan yang berada dalam kondisiLPBTD yang bersumber dari EM lebih tinggi dibandingkan perusahaan dalamLPBTD yang tidak bersumber dari EM. Kondisi ini mungkin saja terjadi karena tindakan manajemen laba yang dilakukan manajer dipandang dari sisi efficiency contracting perspective. Menurut Holthausen (1990), manajemen laba diklasifikasikan sebagaitindakan yang efisien jika diperuntukkan memaksimumkan nilaiperusahaan.

Pada H2 diprediksi bahwa perencanaan pajak sebagai sumber LPBTD akan memperkuat persistensi laba. Koefisien $\mathrm{PTBI}_{\mathrm{it}} \mathrm{XTP}_{\text {it }}$ akan diprediksi bernilai positif $\left(\gamma_{5}>0\right)$. Dalam Tabel 4, hasil pengujian $\mathrm{H}_{2}$ menunjukkan bahwa koefisien $\gamma_{5}$ bernilai $-0,011\left(\gamma_{5}<0\right)$ dan tidak signifikan. Dengan demikian $\mathrm{H} 2$ ditolak. Berdasarkan hasil penelitian ini, penulis tidak dapat membuktikan bahwa kualitas laba perusahaan yang berada dalam kondisiLPBTD yang bersumber dari TP lebih tinggi dibandingkan perusahaan dalamLPBTD yang tidak bersumber dari TP.

Hasil tersebut sejalan dengan hasil penelitian Blaylock et al. (2012).Menurut Blaylock et al. (2012), pembayaran pajak yang rendah akan menghasilkan cash effective tax rate yang rendah. Selain itu, jika perusahaan menaikkan beban atau pajak tangguhan untuk kepentingan perpajakan (perencanaan pajak), maka akan menghasilkan adalah cash effective tax rate yang rendah. Dari sini dapat disimpulkan bahwa pengukuran cash effective tax ratetidak dapat ditinjau dengan periode 5 (lima) tahun.
Tabel 4.6

Hasil Estimasi Persistensi Laba

\begin{tabular}{|c|c|c|c|c|}
\hline Variabel & \begin{tabular}{|c|}
$\begin{array}{c}\text { Prediksi } \\
\text { tanda }\end{array}$ \\
\end{tabular} & Koefisien & Prob. & Keterangan \\
\hline $\begin{array}{l}\text { Konstanta } \\
\left(\gamma_{0}\right)\end{array}$ & & $-0,034$ & 0,094 & \\
\hline $\mathrm{EM}_{\mathrm{it}}\left(\gamma_{1}\right)$ & & $-0,076$ & 0,089 & \\
\hline $\mathrm{TP}_{\mathrm{it}}\left(\gamma_{2}\right)$ & & 0,007 & 0,434 & \\
\hline $\begin{array}{l}\text { PTBI }_{\text {it }} \\
\left(\gamma_{3}\right)\end{array}$ & & 1,068 & 0,000 & \\
\hline $\begin{array}{l}\text { PTBI }_{\text {it }} \quad x \\
\text { EM }_{\text {it }}\left(\gamma_{4}\right)\end{array}$ & $(-)$ & 1,013 & 0,021 & H1ditolak \\
\hline $\begin{array}{l}\text { PTBI }_{\text {it }} \quad \mathrm{x} \\
\operatorname{TP}_{\text {it }}\left(\gamma_{5}\right)\end{array}$ & $(+)$ & $-0,011$ & 0,480 & H2ditolak \\
\hline $\begin{array}{l}\text { Adjusted } \mathrm{R}^{2} \\
\text { F-statistik }\end{array}$ & \multicolumn{4}{|c|}{$\frac{1}{0,745}$} \\
\hline $\begin{array}{l}\text { Prob. } \\
\text { statistik }\end{array}$ & (F- & \multicolumn{3}{|c|}{0,000} \\
\hline
\end{tabular}

Sumber: Hasil pengolahan data

\section{KESIMPULAN}

Penelitian ini adalah replikasi dari penelitian Blaylocket al. (2012). Tujuan dari penelitian ini adalah untuk menganalisis pengaruh manajemen laba dan perencanaan pajak sebagai sumber LPBTD terhadap persistensi laba pada perusahaan yang berada dalam kondisi LPBTD. Namun demikian, penulis tidak dapat membuktikan hipotesis yang dikembangkan dalam penelitian ini. H1ditolak karena hasil regresi justru menunjukkan sebaliknya. Dalam hal ini, kualitas laba perusahaan yang berada dalam kondisiLPBTD yang bersumber dari EM lebih tinggi dibandingkan perusahaan dalamLPBTD yang tidak bersumber dari EM. Kondisi ini mungkin saja terjadi karena tindakan manajemen laba yang dilakukan manajer dipandang dari sisi efficiency contracting perspective.

H2ditolak lantaran penulis tidak dapat membuktikan bahwa kualitas laba perusahaan yang berada dalam kondisiLPBTD yang bersumber dari TP lebih tinggi dibandingkan perusahaan dalamLPBTD yang tidak bersumber dari TP. Hasil tersebut sejalan dengan hasil penelitian Blaylock et al. (2012).Menurut Blaylock et al. (2012), pengukuran cash 
effective tax rate tidak dapat ditinjau hanya dengan periode 5 (lima) tahun.

Tidak dapat dibuktikannya pengaruh manajemen laba dan perencanaan pajak sebagai sumber LPBTD terhadap persistensi laba di sini mungkin terjadi karena jumlah sampel yang terpilih pada penelitian ini sangat terbatas. Untuk penelitian selanjutnya, diharapkan dapat memperluas periode penelitian serta mencari proksi manajemen laba dan perencanaan pajak yang lebih baik. Selain itu, peneliti selanjutnya tidak hanya membatasi pada pengujian persistensi laba saja, tetapi juga pengaruh manajemen laba dan perencanaan pajak sebagai sumber LPBTD terhadap nilai perusahaan. Hal ini ditujukan untuk memastikan apakah motivasi manajer dalam melakukan manajemen laba termasuk dalam opportunistic behavior perspectiveatauefficiency contracting perspective.

\section{Daftar Pustaka}

Blaylock, B., Shevlin, T., \& Wilson, R. (2012). Tax avoidance, large positive book-taxdifferences, and earnings persistence. The Accounting Review, 87, 91-120.

Hanlon, M. (2005). The persistence and pricing of earnings, accruals and cash flows when firms have large book-tax differences. The Accounting Review, 80, 137-166.
Darusallam, Septriadi, D. (2009). Tax avoidance, Tax planning, Tax evasion, and Anti Avoidance Rule. 22 Juli 2009.

Dyreng et al. (2008). Long-run corporate tax avoindance. The Accounting Review 83

Ghozali, I. (2009). Aplikasi analisis multivariate dengan Program SPSS. Semarang: Badan Penerbit Universitas Diponegoro.

Kothari, et al. (2005). Performance matched discretionary accrual measure. Journal of Accounting and Economics, 39, 163-197

Penman, S. H. (2001). Financial statement analysis and security valuation. Singapore: Mc Graw Hill.

Phillips, J., Pincus, M., \& Rego, S. O. (2003). Earnings management: New evidence based on deferred tax expense. The Accounting Review, 78, 491-521.

Scott, R. W. (2000). Financial accounting theory, 2nd Ed. New Jersey: Prentice Hall.

Sloan, R. G. (1996). Do stock prices fully reflect information in accruals and cash flows about future earnings?.The Accounting Review, 71, 289-315.

www.idx.com 
